Iran Journal of Nursing (IJN)

Vol 32, No. 117, Apr 2019: 33- 47

\title{
The Correlation of Emotional Intelligence and Self-efficacy in Patients with Intestinal Stoma
}

\author{
Fariba Nasiri Ziba ${ }^{1}$, Maryam Saati ${ }^{2}$, Hamid Haghani ${ }^{3}$
}

\begin{abstract}
Background \& Aims: Patients with intestinal stoma experience periods of psychological and physical disorders, including disturbances in self-efficacy, which has always been a serious issue for these patients. This is mainly due to the fact that one of the most important challenges of a patient following stoma implantation is how to take care of the stoma, be present in the society with the stoma, carry out daily activities and work. Lack of ability to care for the stoma will lead to the gradual isolation of the person from society, friends, and even family and their failure to effectively communicate with the society. Focusing on patients' level of efficiency and the related factors in this area by healthcare providers, especially nurses who have the most contact with patients during the first postoperative days, is crucial. On the other hand, it is presumed that factors such as emotional intelligence could be associated with self-efficacy in these patients. Given that the present study is the basis for future studies, evaluation of the factors related to self-efficacy can be considered in the provision of the type of education to patients in future interventions so that nurses would give better education to patients in the future. Therefore, the present study aimed to determine the correlation between emotional intelligence and self-efficacy in patients with an intestinal stoma.
\end{abstract}

Materials \& Methods: This descriptive-correlational study was conducted on 155 patients (79 men and 76 women) with an intestinal stoma (colostomy and ileostomy) referring to the selected hospitals affiliated to Iran University of Medical Sciences and Iranian Ostomy Association in 2018. The inclusion criteria were willingness to participate in the research, being literate, a minimum age of 18 years, passing of at least one month from the surgery, having an intestinal stoma (colostomy or ileostomy), and having no known psychological disorders. On the other hand, the exclusion criteria were disabilities and movement disorders in hand to write and answer the questionnaire, unwillingness to participate in the study, and incomplete questionnaires. The patients were selected via convenience sampling, and data were collected using a demographic questionnaire, ostomy self-efficacy questionnaire (with two dimensions of social self-efficacy and ostomy care self-efficacy), and Schutte self-report emotional intelligence test (with three dimensions of emotion regulation, evaluation, and expression of emotion, exploitation of emotion). Data collection was carried out during August $16^{\text {th }}$-December $13^{\text {th }}, 2018$.

Data analysis was performed in SPSS version 16 using descriptive statistics (absolute frequency and frequency percentage (for qualitative variables), mean and standard deviation (for quantitative variables), as well as Pearson's correlation coefficient, independent t-test, and analysis of variance (ANOVA).

Results: In this study, the mean age of the participants was 54.33 years (minimum and maximum ages of 18 and 86 years, respectively). In total, $51 \%$ of the subjects were male and $49 \%$ were female. In addition, $74.2 \%$ of the participants were married, 9.7\% were single and $6.1 \%$ were divorced/widowed. According to the results, only $16.1 \%$ of the patients had an academic education, and $69 \%$ of the patients had at least one helper for their stoma care while $31 \%$ took care of their stoma alone. Overall, $53 \%$ and $47 \%$ of the patients underwent ostomy due to cancer and other causes (e.g., intestinal inflammation, Crohn's disease, irritable bowel syndrome, intestinal obstruction, trauma, constipation or chronic diarrhea, incontinence, and diverticulitis), respectively. It had been more than one, one-five, and five years since the ostomy of $69.7 \%, 16.8 \%$, and $13.5 \%$ of the participants, respectively. Moreover, $24 \%$ of the patients changed their jobs following an ostomy. According to the results, there was a significant relationship between emotional intelligence and self-efficacy $(\mathrm{r}=0.49, \mathrm{P}=<0.001)$. furthermore, a direct and significant correlation was found between emotional intelligence and self-efficacy

\footnotetext{
${ }^{1}$. Lecturer, Medical Surgical Department, School of Nursing and Midwifery, Iran University of Medical Sciences, Tehran, Iran

${ }^{2}$. MS Student, Medical-Surgical Nursing Department, School of Nursing and Midwifery, Iran University of Medical

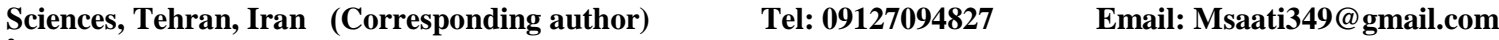

3 . Lecturer, Department of Biostatistics, School of Health, Iran University of Medical Sciences, Tehran, Iran
} 
dimensions, where a higher correlation was observed in the dimension of social self-efficacy $(r=0.53)$, compared to the dimension of stoma care $(r=0.29)$. In addition, the correlation between the dimensions of emotional intelligence and total self-efficacy was almost equal. Among the dimensions of emotional intelligence and selfefficacy, the highest and lowest correlations were observed between the dimension of social self-efficacy and emotion regulation $(\mathrm{r}=0.52)$ and between stoma care and exploitation of emotion $(\mathrm{r}=0.24)$, respectively. Tukey's test results demonstrated that while no significant relationship was observed between emotional intelligence and demographic characteristics of patients, the self-efficacy score of married participants was 11.09 units higher than that of divorced or widowed subjects, which was statistically significant $(\mathrm{P}=0.02)$. In other words, married patients had a higher self-efficacy level.

Conclusion: Patients with an intestinal stoma have impaired self-efficacy, especially in the area of social selfefficacy. Given the higher levels of self-efficacy in patients with higher emotional intelligence, it is recommended that a positive step be taken to increase the self-efficacy of these patients, especially in the field of social selfefficacy, by planning and implementing educational interventions in the area of emotional intelligence. Notably, the emotion regulation component had a higher correlation with social self-efficacy. Since the mentioned dimension is related to the social interactions of patients with a stoma, it is suggested that more attention be paid to this dimension as a dimension that was more impaired than the self-efficacy of ostomy care in this study to improve social self-efficacy. Moreover, our findings can be applied in continuous nursing education, which will increase the sensitivity of nurses about physical and mental changes of patients undergoing an ostomy. By using these findings, nurses can design and implement more suitable educational programs for patients.

\section{Keywords: Emotional Intelligence, Self-efficacy, Intestinal Stoma, Ostomy}

\section{Conflict of Interest: No}

How to Cite: Nasiri Ziba F, Saati M, Haghani H. The Correlation of Emotional Intelligence and Self-efficacy in Patients with Intestinal Stoma. Iran Journal of Nursing. 2019; 32(117):33-47.

Received: 9 Jan 2019

Accepted: 13 Apr 2019 


\title{
همبستى هوش هيجانى با خودكار آمدى در بيماران دار ایى استومى كوارشى
}

\author{
فريبا نصيرى زيبا'، مريم ساعتى '، حميد حقانى
}

جكيده

زمينه و هدف: بيماران داراى استومى كوارشى دورههايى از تنشهاى روانى و جسمى از جمله اختلال در خودكار آمدى را تجربه مى كنند. تصور مىشود

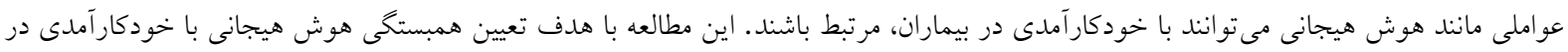
بيماران داراى استومى گوارشى انجام شده است. روش بر رسى: اين يزٔوهش يك مطالعه توصيفى همبستخى بود كه با همكارى 100 نمونه (V9 مرد، V7 زن) بيمار داراى استومى كوارشى ( كلستومى و

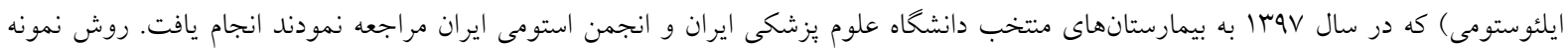

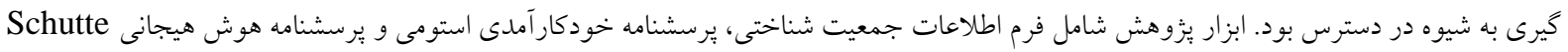

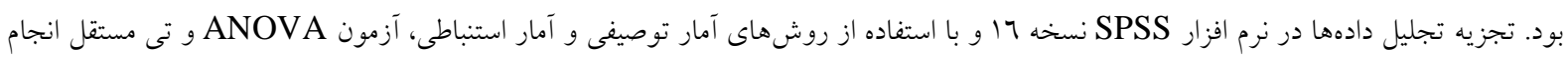

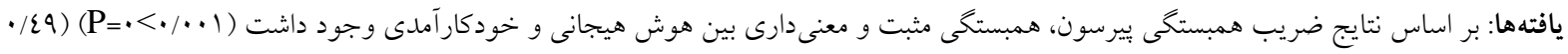

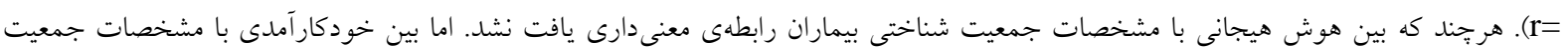

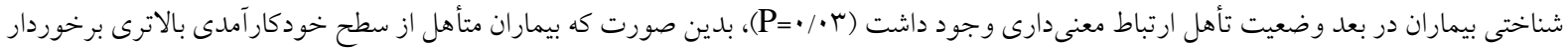
نتيجه گيرى كلى: بيمارانى كه هوش هيجانى بالاترى داشتند از سطوح خودكارآمدى بالاترى نيز برخوردار بودند، توصيه مىشود با برنامه ريزى و اجراى

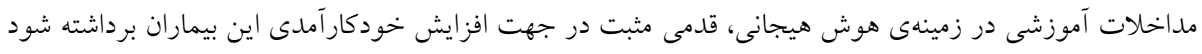

\section{كليد وازهها: هوش هيجانى، خودكار آمدى، استومى گوارشى، استوما}

تعارض منافع: ندارد

تاريخ دريافت: 9V/1 •

تاريخ بذيرش:

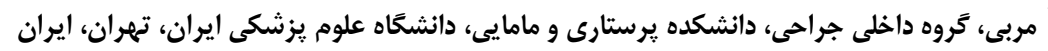

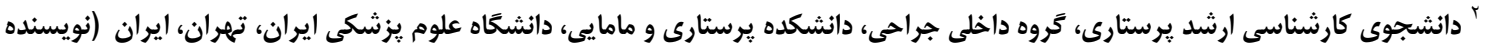


مراقبت سلامت كه به بسترى طولانىتر بيماران و افزايش

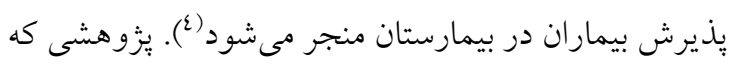

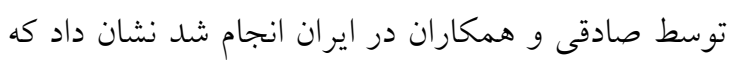
مانند ديخر عوارض، مشكلات روانشناختى در بين بيماران

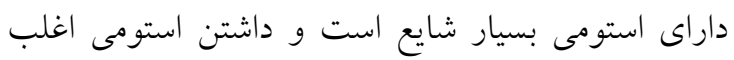
سبب تغيير و مشكلاتى در تعاملات اجتماعى، ملاحظات

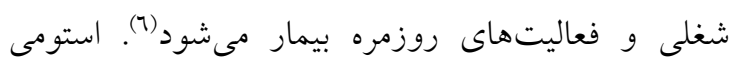
كوارشى تأثير بسيار زيادى بر عملكردهاى اجتماعى اين دوزئ

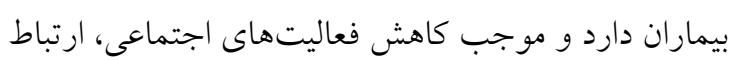

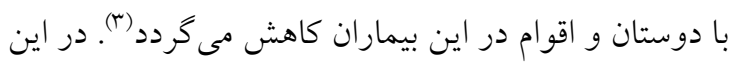

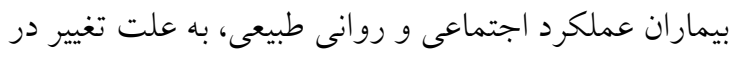

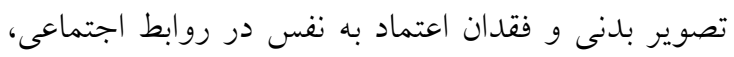
تخريب مىشود (v). بيماران اغلب در ورنماد به نفر در روبط كردن،

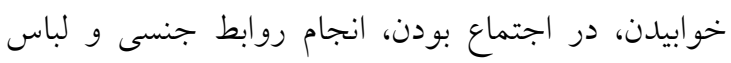

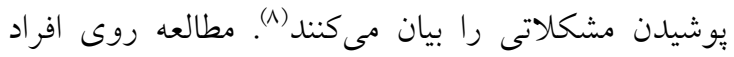

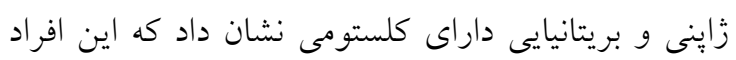

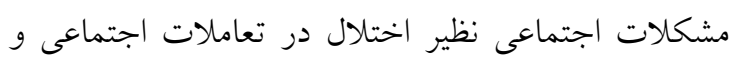

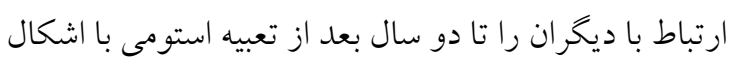

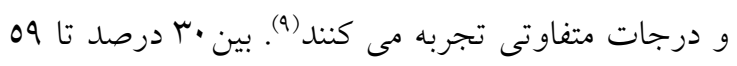
درصد بيماران داراى استومى، در فعاليتهاى روزمرهى نئه زندكى محدوديتهايى داشتند. به طورى كه دimmons

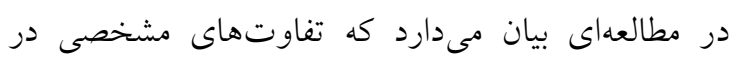
تعاملات اجتماعى بيماران داراى استومى و كسانى كه بدون

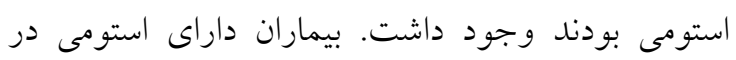

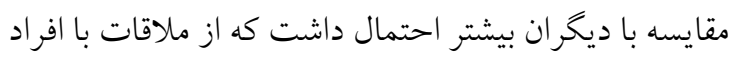
جديد اجتناب ورزند و كمتر احتمال مىرفت كه در فعاليت

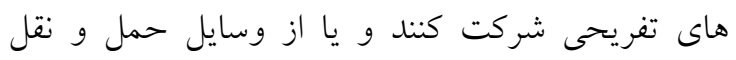
عمومى استفاده كنند (·). بيماران داراى استومى، معمولاً به ونه

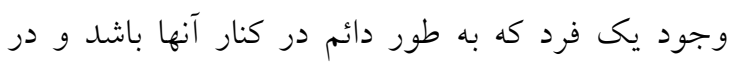

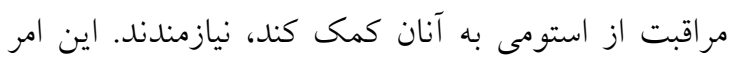
براى آنها يك ضرورت ناخوشايند است كه بصورت اختلال در خودكارآمدى اين بيماران ظهور مى بيابد. خودكار آمدى يا كار آيى شخصى يكى مفهوم روانى اجتماعى إنى

\section{مقدمه}

استومى كوارشى به عنوان يكى دهانه در ناحيهى شكم به

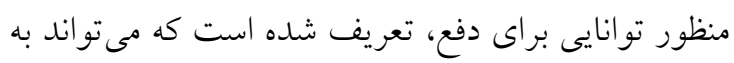

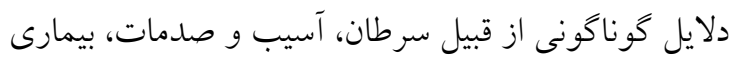

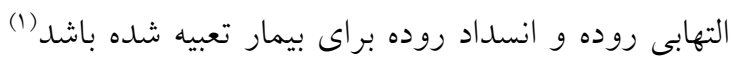
سرطانهاى كولوركتال يكى از علل مهم و اصلى در نياز

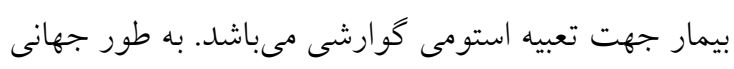
سرطانهاى كولوركتال سومين سرطان شايع در بين مردان بعد از سرطان ريه و يروستات و دومين سرطان در بين زنان بعد از سرطان بِتان مىباشند. با اين حال مواردى از تعبيه

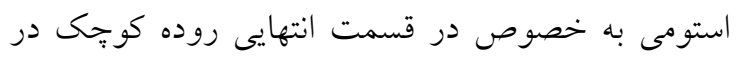

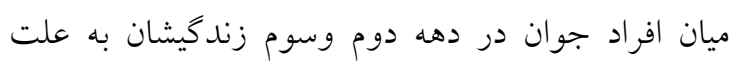

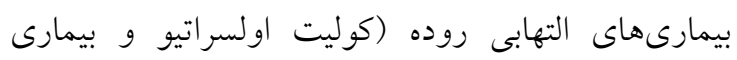

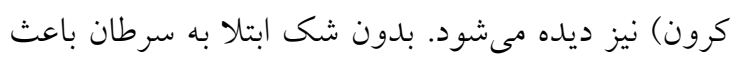

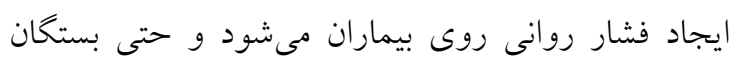

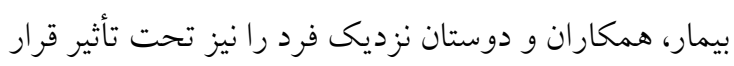
مىدهد (r). آخرين تخمين جهانى از سرطان وهاى كولور كتال،

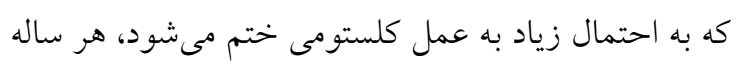

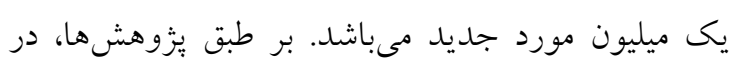

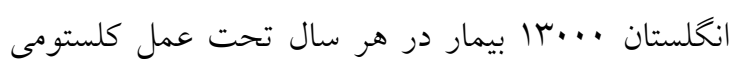

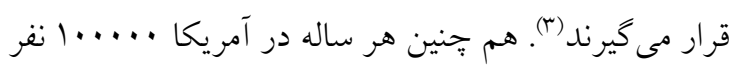
تحت عمل تعبيه كلستومى يا ايلئوستومى قرار مى كيرند (ع). بر اساس آمار اداره سرطان مركز مديريت بيماريها در سال

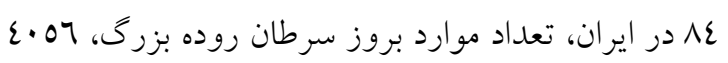

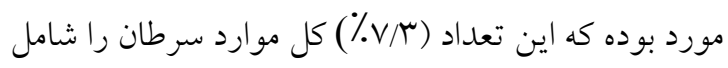

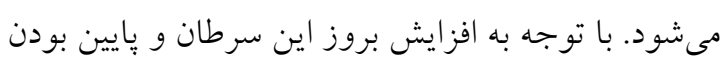

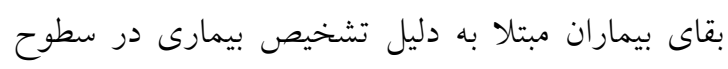

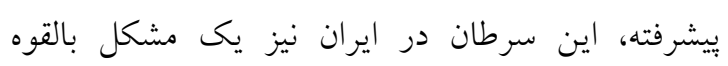

$$
\text { محسوب مىشود }
$$
با وجود اين كه عمل كلستومى يكى عمل جراحى متداول

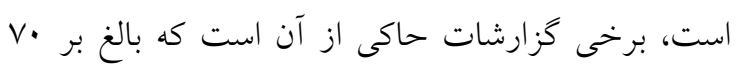

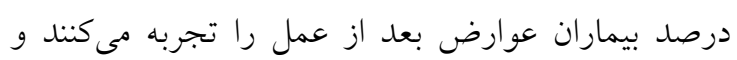
داشتن عارضه مساوى است با هزينههاى بالا براى سيستم 
فرد حاصل مىشود. مهارتهاى هوش هيجانى هم تجنين

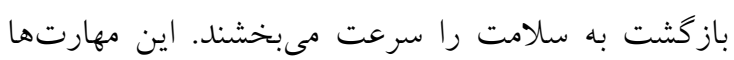

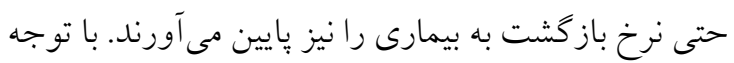

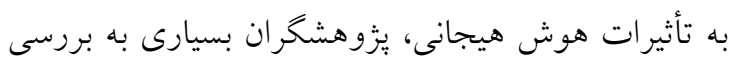

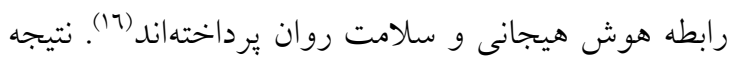

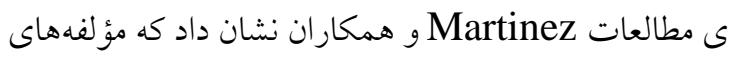
هوش هيجانى قادر به بيش بينى سلامت روان مىباشند. يثزوهشهاى فرا تحليلى نيز نشان دادهاند كه هوش هيجانى يكى از مهمترين متغيرهاى بيش بينى كنندهى سلامت روان

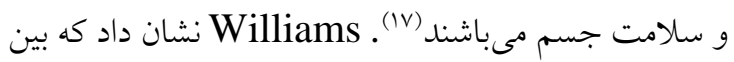

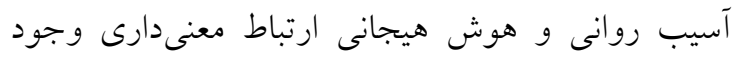

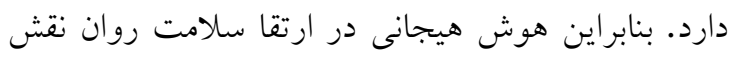

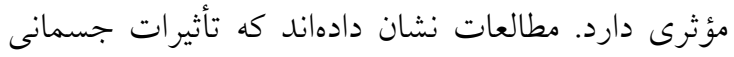
هوش هيجانى به قدرى است كه با عكس بردارى از مغز

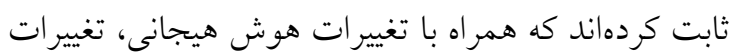
فيزيولوزيكى در مغز شكل مى كيرد (1).

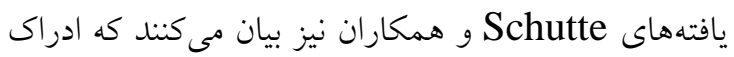

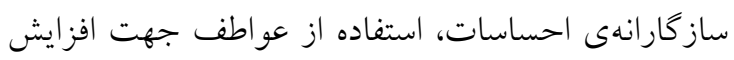

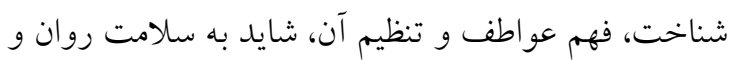

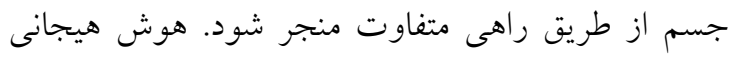

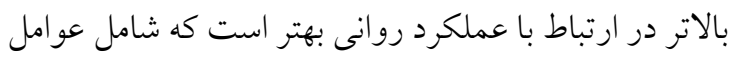
درون فردى مانند خوش بينى و عوامل بين فردى مانند

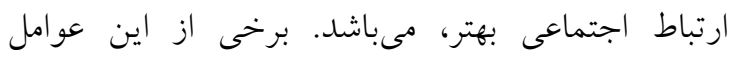

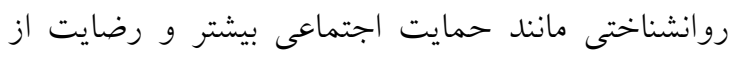

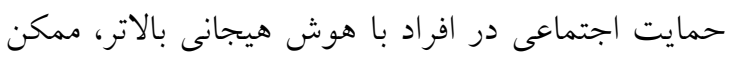
است به عنوان سيرى در مقابل بيمارىهاى جسمى عمل كنند، به علاوه افرادى كه داراى هوش هيجانى بالاترى هستند، ممكن است از رفتارهاى بهاشاشتى بهتر بيروى كنند كه اين نشان دهندهى انطباق آنان با برنامهى درمانى است(19). با توجه به بررسىهاى انجام شده، مشكلات

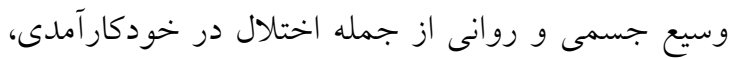

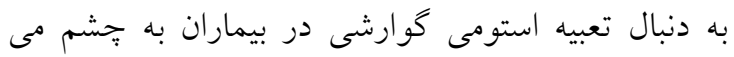
خورد كه اين اختلالات روانى و اجتماعى مدتها محققان

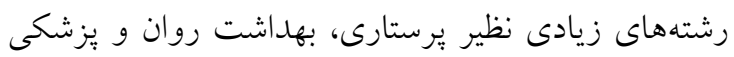

است كه از نظريه يادگيرى اجتماعى Albert Bandura

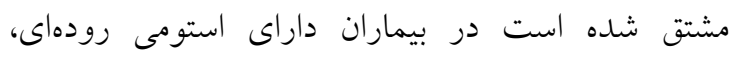

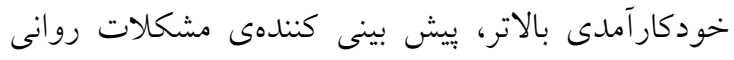

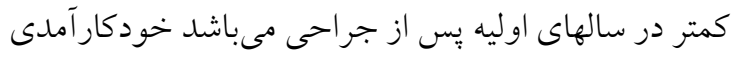

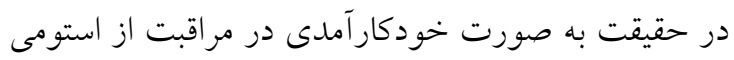

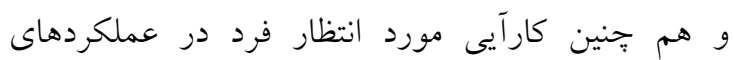

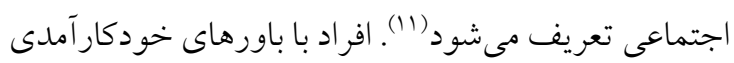

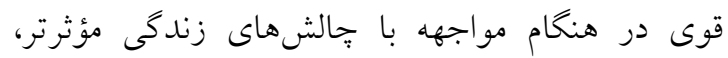

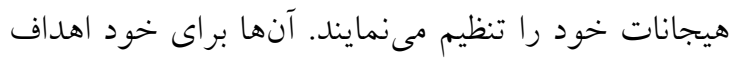
بزرگترى درنظر مى گيرند، سعى و كوشش بيشترى به به خرج

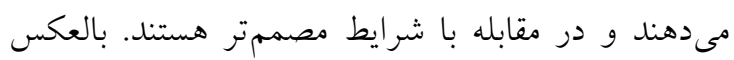
افرادى كه خودكارآمدى پايينى دارند، احساس مى كنند در كنترل بر رويدادهاى زندكى درمانده و ناتوانند. آنها معتقدند هركونه تلاشى كه مى كنند بيهوده است و ونديلدين

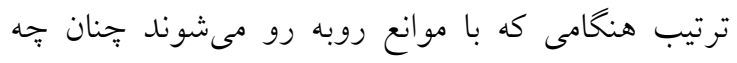

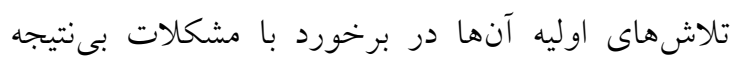

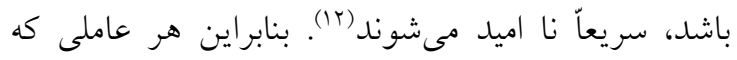

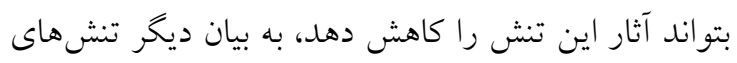

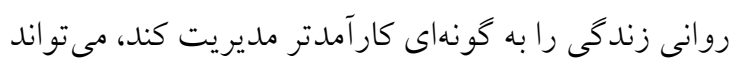

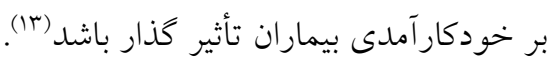

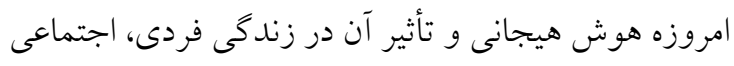

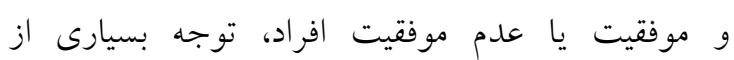

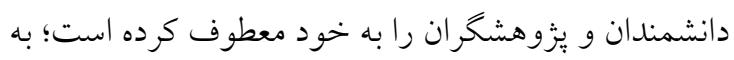
طورى كه •م درصد موفقيت انسانها را به هوش هيجانى

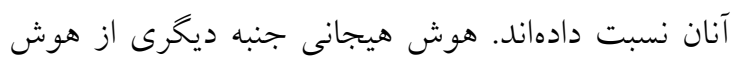

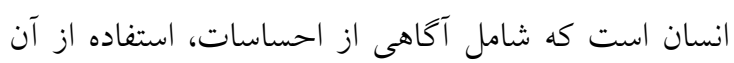
براى كرفتن تصميمهاى مناسب در زندكى و هم جنين آنين

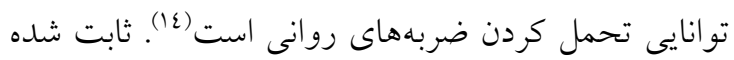

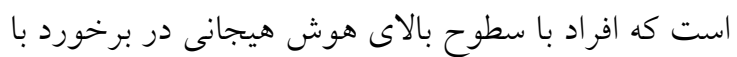

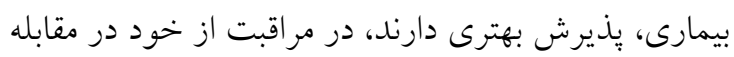

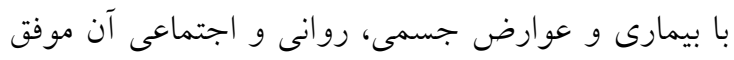

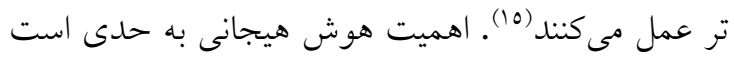

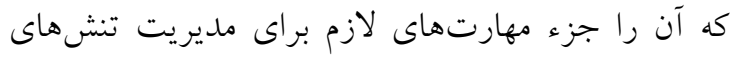

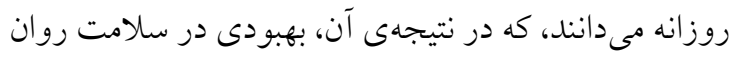


از مقداركذارى در فرمول زير حجم نمونه تعداد 100 نفر بر آورد كرديد.

$$
w=\frac{1}{2} \ln \frac{1+r}{1-r}
$$

معيارهاى ورود به مطالعه شامل تمايل بيمار به شركت در

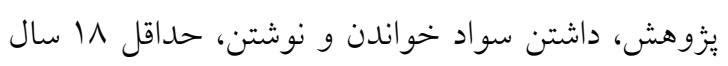

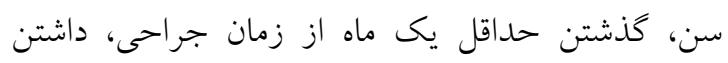

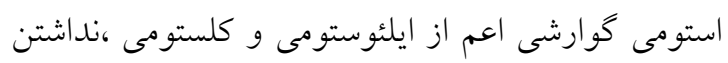

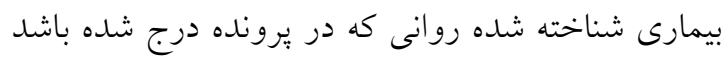

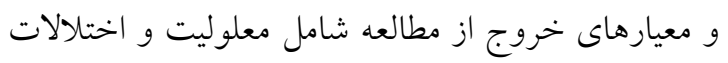
حركتى در دست جهت نخارش و پاسخخ به يرسشنامه،

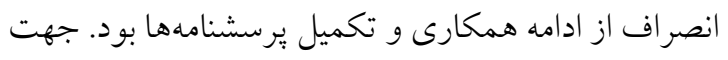

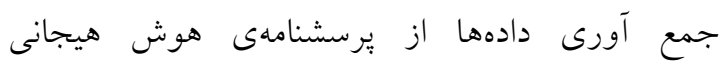
The Schutte self report و هم هونشاران Schutte و (emotional intelligence test (SSEIT) stoma self ) يرسشنامهى خودكارآمدى استومى كه توسط Befficacy scale طراحى شده است استفاده شد (·r). فرم اطلاعات جمعيت توست

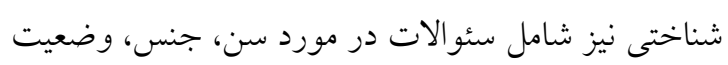

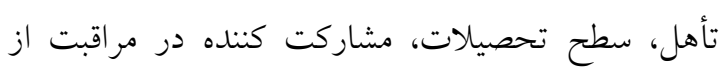

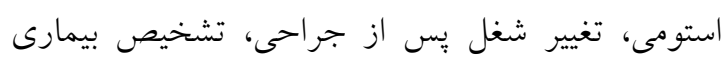

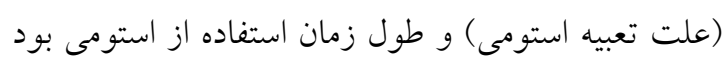

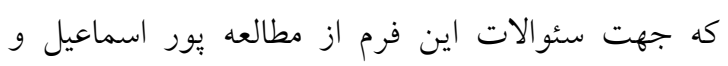

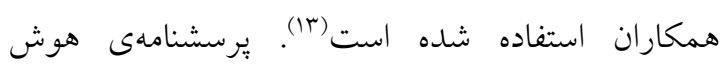

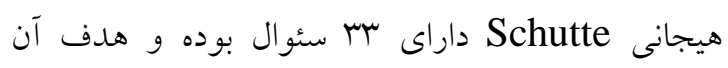
سنجش مؤلفههاى هوش هيجانى (تنظيم هيجان، ارزيابى هئ دان

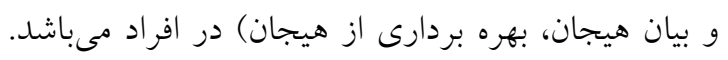
امتيازات بر طبق رتبه بندى ليكرت از كاملاً مو افقم با امتياز

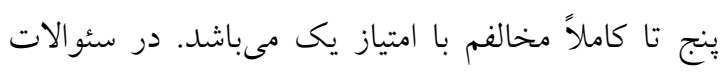

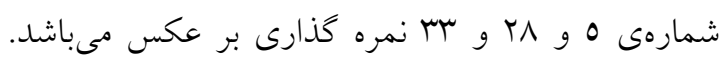

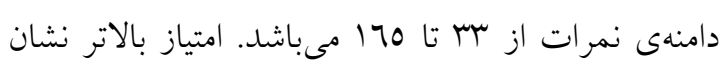

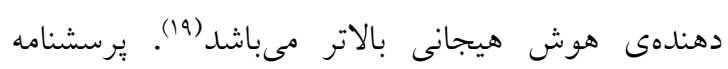

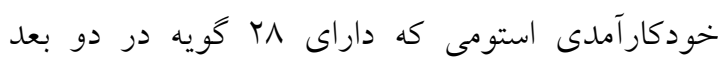

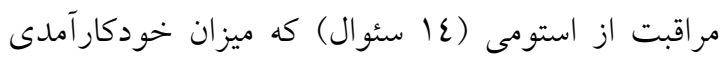

اجتماعى را به خود جذب كرده است(·)، لازم به ذكر است كه اختلال در خودكارآمدى همواره به عنوان يكى مسئله

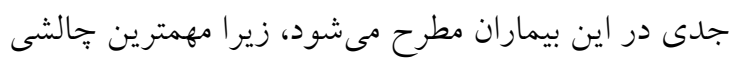

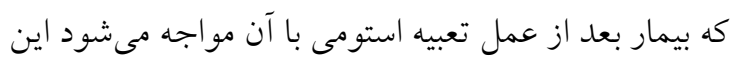

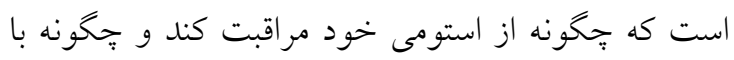
وجود داشتن استومى در اجتماع حضور يابد و به فعاليت

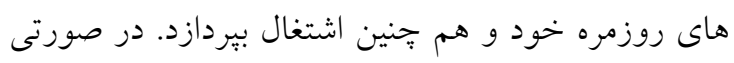

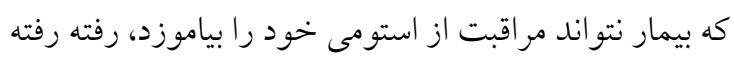

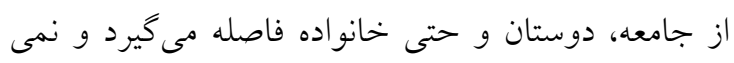
تواند به طور كارآمد و مؤثر با جامعه ارتباط برقرار كند.

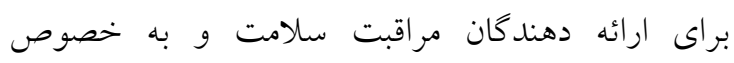

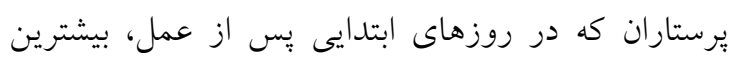

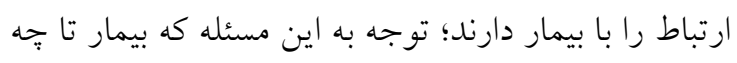

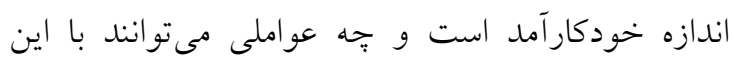
موضوع در ارتباط باشند، امرى ضروريست، با توجه به اينكه مطالعه حاضر، مبنايى براى انجام مطالعات آينده

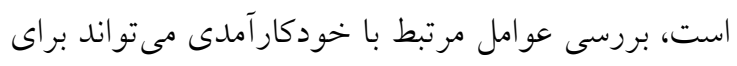

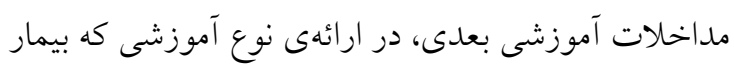

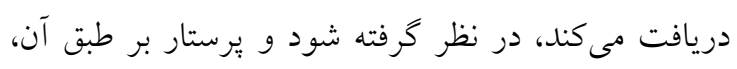

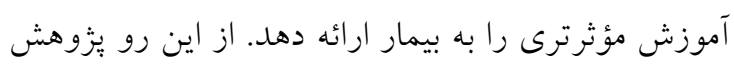

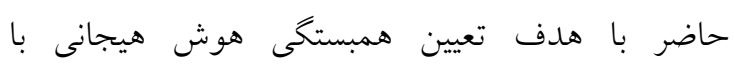
خودكارآمدى در بيمار ان داراى استومى كوارشى انجام شد. هون.

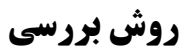

اين مطالعهى توصيفى از نوع همبستخى بود، كه در سال

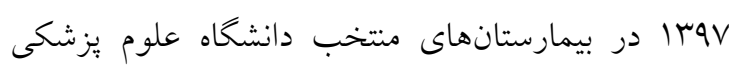

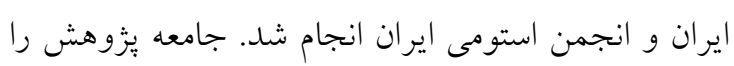

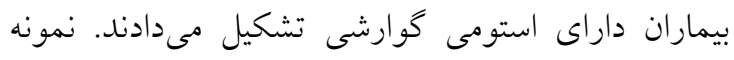

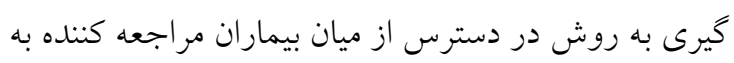

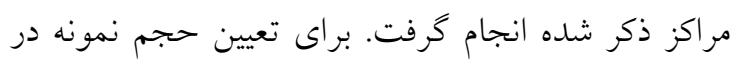

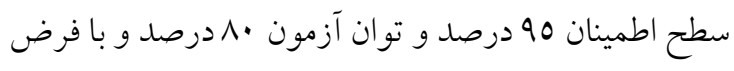

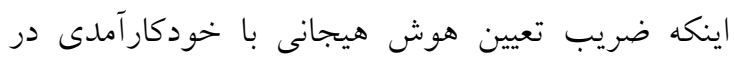

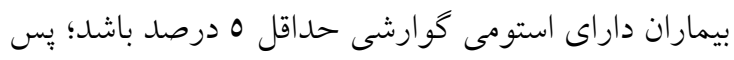


تكميل، ير سشنامهها در همان روز جمع آورى مىشد.جمع

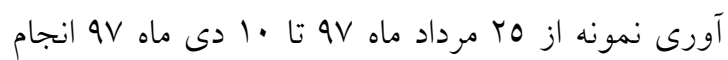

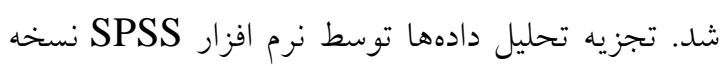
17 انجام گرفت. براى توصيف مشخصات نمونهها از آمار توصيفى شامل توزيع فراوانى مطلق و درصد فراوانى

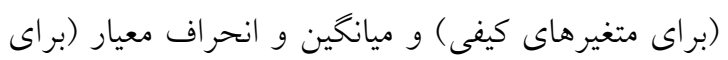

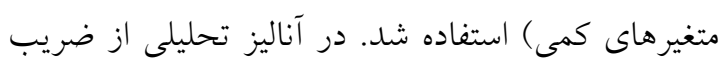
همبستخى ييرسون، آزمون تى مستقل، ANOVA و و آناليز

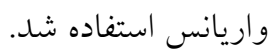

\section{يافتهها}

ميانكين سنى بيماران شركت كننده در يزوهش بآ/عه سال

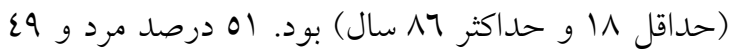
درصد زن، / V V درصد متأهل و 9/V درصد مجرد و | IV/ درصد بيوه يا مطلقه بودند. تنها ال17/ درصد از بيماران

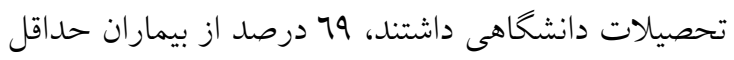
يكى نفر را جهت مشاركت در امر مراقبت از استومى را دارا

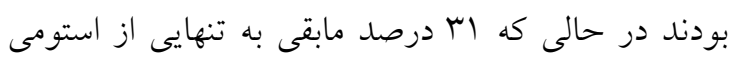

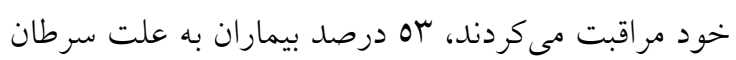

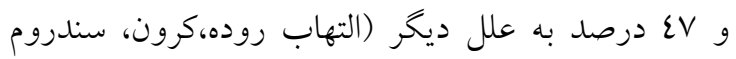
روده تحريك يذّير، انسداد روده، تروما، يبوست يا دئ اسهال

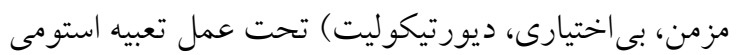
كوارشى قرار گرفته بودند كه 79/V درصد از بيماران كمتر

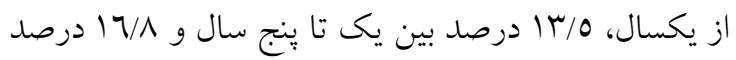

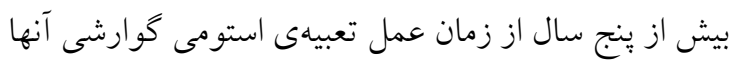

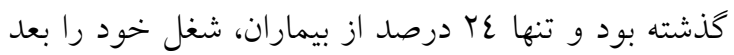

از استومى گوارشى تغيير داده بودند (جدول شماره ().
مورد انتظار فرد را در مراقبت از استومى مىسنجد و خودكارآمدى اجتماعى (ع ا سئوال) كه كار آيى مورد انتظار فرد در عملكردهاى اجتماعى مرتبط با استوما را مى سنجلد.

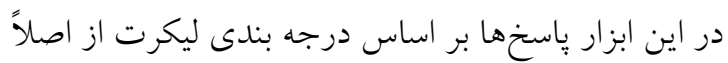

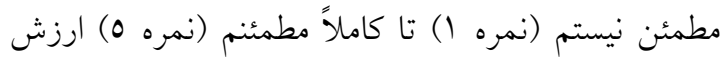
كذارى شده است. مجموع امتيازات ابزار حداقل ^ب (يايين

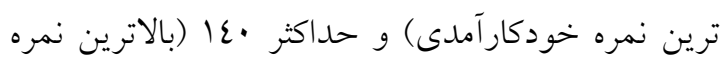

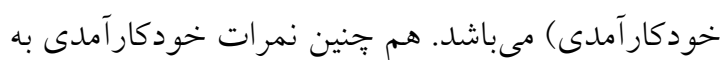
صورت جداكانه در هر يك از ابعاد دامنه (بعد مراقبت از

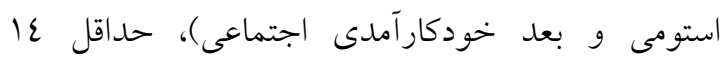

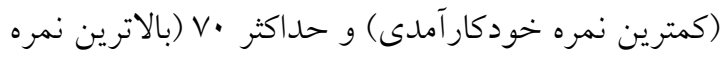
خودكارآمدى) مىباشد، امتياز بيشتر نشان دهنده

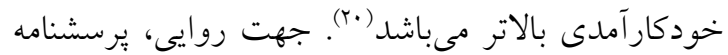

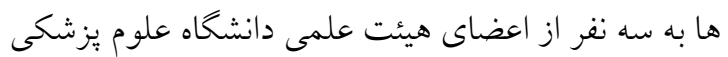
ايران ارائه و روايى آن به شيوه روايى محتوا و و صورى تأييد

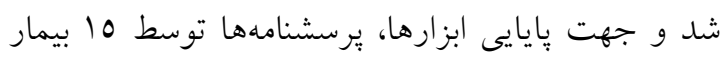

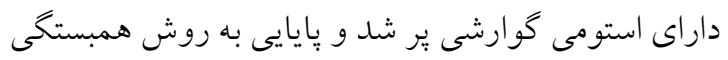

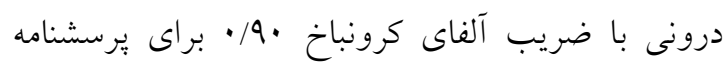

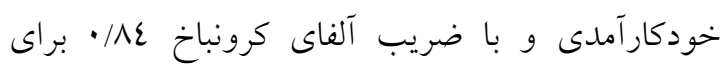
برسشنامهى هوش هيجانى تأييد شد. بِ بس از تأييديه كميته

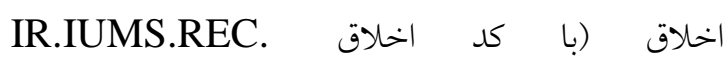

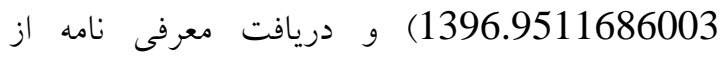

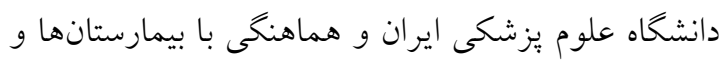

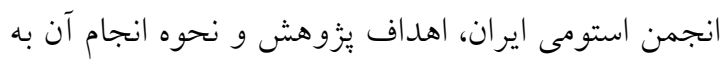

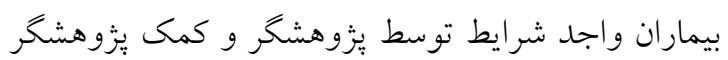
توضيح داده مىشد و بعد از كرفتن رضايت كتبى از

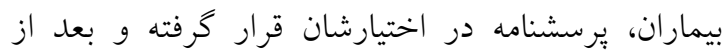

جدول شماره ا: توزيع فراوانى متغير هاى جمعيت شناختى و بيمارى نمونههاى مورد مطالعه از بيماران داراى استومى توارشى در بران بيمار ستان

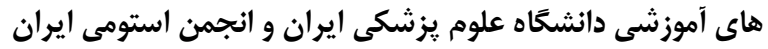

\begin{tabular}{|c|c|c|c|}
\hline ل ا درصد & فراوانى & حالت & 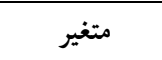 \\
\hline or & $\wedge 1$ & سرطان دستكاه كوارش & نوع بيمارى \\
\hline$\varepsilon v$ & v) & بيمارى هاى التهابى روده و ديخر علل ذكر شده & \\
\hline$V \varepsilon / r$ & 110 & متاهل & \\
\hline $9 / \mathrm{V}$ & 10 & مجرد & وضعيت تاهل \\
\hline $17 / 1$ & ro & بيوه/ مطلقه & \\
\hline
\end{tabular}




\begin{tabular}{|c|c|c|c|}
\hline$r \varepsilon$ & rV & بله & \multirow[t]{2}{*}{ تعيير شغل پِ از تعبيه استومى } \\
\hline $\mathrm{V} 7$ & $11 \mathrm{~V}$ & 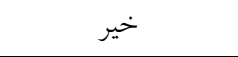 & \\
\hline$M_{1}$ & $\varepsilon \wedge$ & تنها & \multirow{5}{*}{ 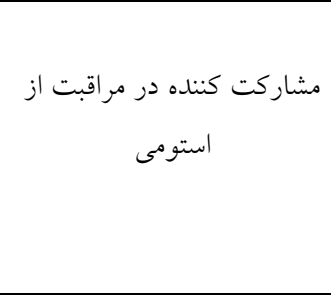 } \\
\hline$r / r$ & 0 & و الدين & \\
\hline$r$. & $\mu_{1}$ & 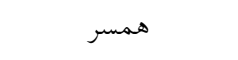 & \\
\hline ro/o & 00 & 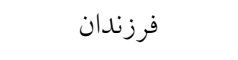 & \\
\hline 9 & $1 \varepsilon$ & مراقبت كننده & \\
\hline $79 / 2$ & $1 \cdot 1$ & از يك ماه تا يكسال & \multirow{3}{*}{ طول زمان استفاده از استومى } \\
\hline $1 \pi / 0$ & YI & يكى سال تا پنج سال & \\
\hline $17 / 1$ & $r 7$ & بيشتر از بنج سال & \\
\hline $17 / 1$ & To & دانشخاهى & \multirow[t]{2}{*}{ تحصيلات } \\
\hline$\Delta r / q$ & ir. & غير دانشخاهى & \\
\hline
\end{tabular}

بود كه دامنه نمرات كسب شده از حداقل Vo تا حداكثر

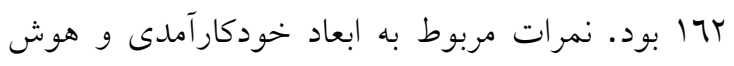

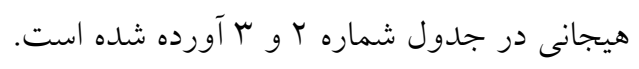

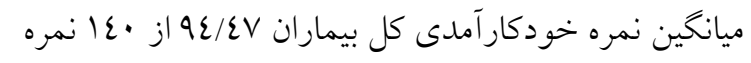
بود كه حداقل نمره ^ع و حداكثر نمره وبا بود. ميانخين نمره كل هوش هيجانى در بيماران

جدول شماره ז: ميانگين نمره هوش هيجانى و مولفه هاى آن در بيماران داراى استومى تَوارشى

\begin{tabular}{|c|c|c|c|c|c|}
\hline حداكثر & حداقل & انحر اف معيار & ميانگين & تعداد & متغير \\
\hline or & rt & $0 / \wedge \varepsilon$ & $\varepsilon 1 / r r$ & 100 & تنظيم هيجان \\
\hline $7 \varepsilon$ & rA & $7 / \cdot 9$ & $0 . / \mathrm{VA}$ & 100 & ارزيابى و بيان هيجان \\
\hline 70 & $r$. & $0 / \varepsilon$. & $0 . / \varepsilon r$ & 100 & بهره بردارى از هيجان \\
\hline $17 r$ & vo & $1 \varepsilon / 0 \varepsilon$ & Irq/VE & 100 & هوش هيجانى (كل) \\
\hline
\end{tabular}

جدول شماره سا: ميانكين نمره خودكار آمدى و مؤلفههاى آن در بيماران داراى استومى كَوارشى

\begin{tabular}{|c|c|c|c|c|c|}
\hline حداكثر & حداقل & انحراف معيار & ميانگين & ت ت تعداد & متغير \\
\hline v. & rA & $9 / 94$ & $O H / 71$ & 100 & مراقبت از استومى \\
\hline$\wedge$. & 17 & $1 r / 19$ & $\varepsilon \cdot / \wedge \uparrow$ & 100 & خودكار آمدى اجتماعى \\
\hline 149 & $\varepsilon \wedge$ & $19 / \cdot 7$ & $q \varepsilon / \varepsilon V$ & 100 & خودكارآمدى (كل) \\
\hline
\end{tabular}

ابعاد خودكارآمدى نيز بيشترين همبستخى بين بعد

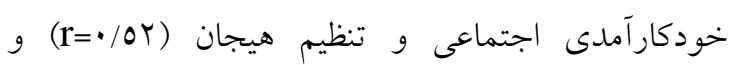
كمترين همبستخى بين بعد مراقبت از استومى و بهره بردارى از هيجان بود ( (r=/r) (جدول شماره ع). نتايج آزمون ANOVA و تى مستقل نشان داد كه بين هوش برد هين هيجانى با مشخصات جمعيت شناختى بيماران ارتباط معنى

$$
\text { دارى وجود نداشت (جدول شماره 0). }
$$

ميانخين نمره هوش هيجانى كل با نمره خودكارآمدى كل

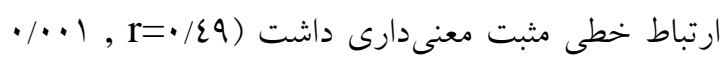
> P). همجنين بين هوش هيجانى و ابعاد خودكارآمدى مئى

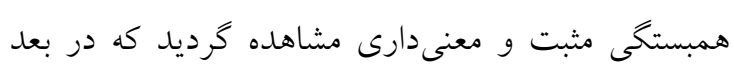

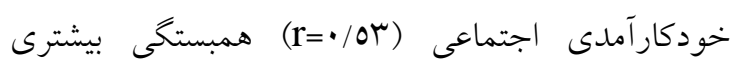
نسبت به بعد مراقبت از استومى (r=•/Yq) وجود داشت. همبستخى بين ابعاد هوش هيجانى با خودكارآمدى كل

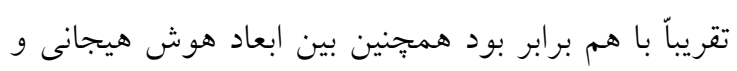




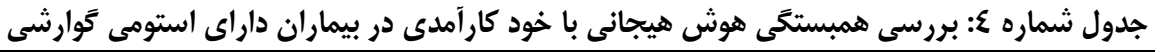

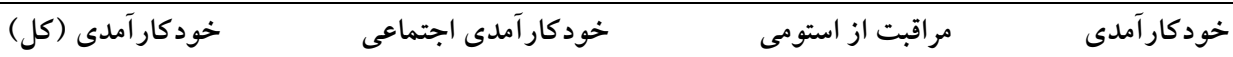

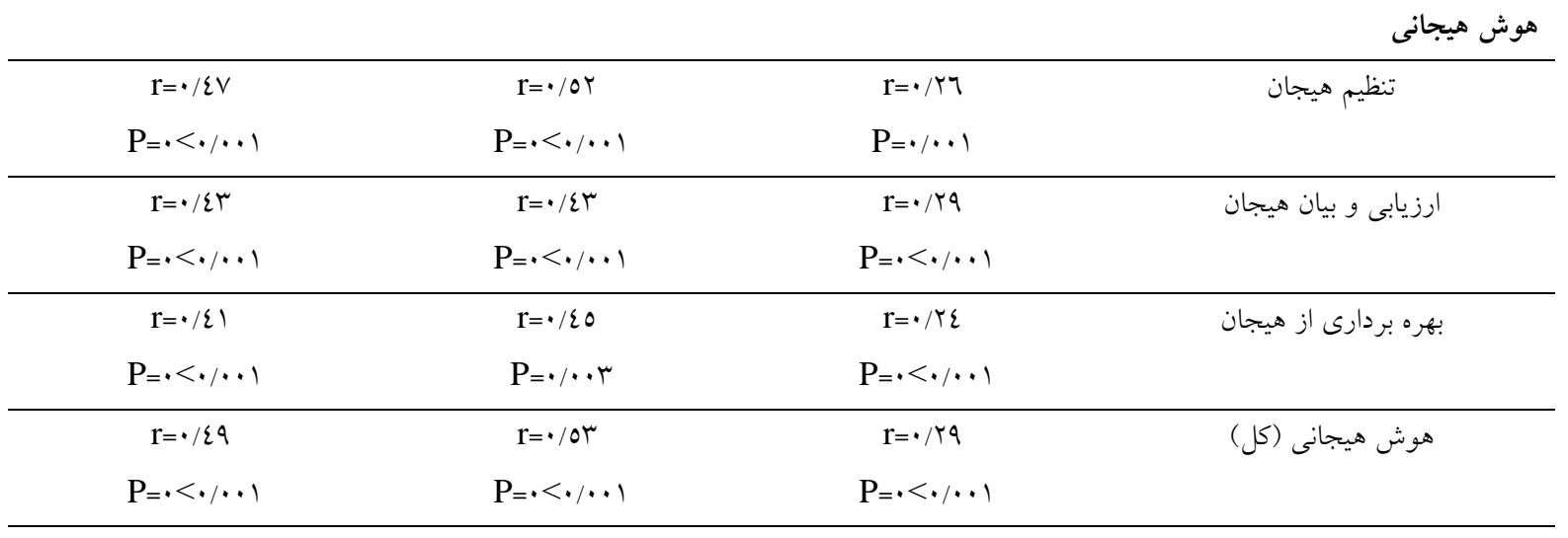

جدول شماره 0: شاخصهاى عددى هوش هيجانى بر حسب مشخصات جمعيت شناختى در بيماران داراى استومى توارشى

\begin{tabular}{|c|c|c|c|c|c|}
\hline نتايج آزمون & انحر اف معيار & ميانكين & تعداد & & \\
\hline \multirow{6}{*}{$\begin{array}{l}\mathrm{f}=\cdot / / 7 \\
\mathrm{P}=\cdot / 0\end{array}$} & $10 / .9$ & $|r q / V|$ & v & كمتر از •r & \multirow{6}{*}{ سن (سال) } \\
\hline & $I \varepsilon / A T$ & ITNNO & $r$. & rq-r. & \\
\hline & IT/AT & $\mid m T / r q$ & $r \varepsilon$ & $\varepsilon q-\varepsilon$. & \\
\hline & $10 / \varepsilon \varepsilon$ & ITINT & $\varepsilon r$ & $09-0$. & \\
\hline & $10 / \Gamma 1$ & $1 r 7 / 09$ & $\varepsilon 1$ & $79-7$. & \\
\hline & $I r / \mu V$ & $1 \% N / 70$ & $r$. & vيشتر از v بي & \\
\hline$t=\cdot / 99$ & $1 r / V V$ & 1TN/O9 & va & مرد & \\
\hline$d f=10 r$ & $10 / \pi 9$ & $1 r \cdot / 9 r$ & v1 & زن & جنسيت \\
\hline \multicolumn{6}{|l|}{$\mathrm{P}=\cdot \pi r$} \\
\hline$f=1 / \pi r$ & IV/AT & $\mid r \cdot / T V$ & 10 & مجرد & \multirow{3}{*}{ وضعيت تأهل } \\
\hline \multirow{2}{*}{$\mathrm{P}=\cdot / r\urcorner$} & $1 \pi / \lambda$ & $|r \cdot / 7|$ & 110 & متاهل & \\
\hline & $10 / 09$ & |ro/2. & ro & بيوه / مطلقه & \\
\hline$f=I / T r$ & $1 \cdot / \Lambda r$ & ITN/TQ & $\varepsilon 9$ & ابتدايى & \multirow{4}{*}{ تحصيلات } \\
\hline \multirow{3}{*}{$\mathrm{P}=\cdot / \mu$} & $17 / r \Lambda$ & $\mid r q / 01$ & \&1 & سيكل & \\
\hline & $17 / 0 r$ & IYN/TY & $\varepsilon$. & دييلم & \\
\hline & $1 \varepsilon / r q$ & $\mid r \varepsilon / N T$ & ro & دانشخاهى & \\
\hline$t=1 / r_{0}$ & $11 / r q$ & $\mid T V / \cdot A$ & $r v$ & بله & \multirow[t]{3}{*}{ تغيير شغل } \\
\hline $\mathrm{df}=10 \mathrm{r}$ & $10 / 2$. & $1 r \cdot / 0 r$ & $11 \mathrm{~V}$ & خير & \\
\hline $\mathrm{P}=\cdot / r \mid$ & & & & & \\
\hline
\end{tabular}

كسانى كه مطلقه يا بيوه بودند 9 •11/ واحد بيشتر بود كه

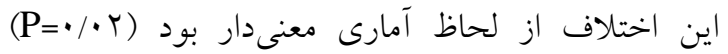

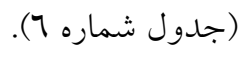

هم جنين بين خودكار آمدى و مشخصات جمعيت شناختى بيماران نيز به جز در مورد وضعيت تأهل ارتباط معنى دارى

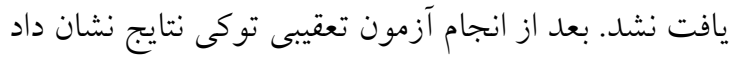

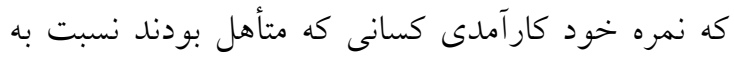




\begin{tabular}{|c|c|c|c|c|c|}
\hline نتايج آزمون & انحراف معيار & ميانخين & تعداد & \multicolumn{2}{|c|}{ متغير } \\
\hline$f=1 / 71$ & $10 / 9 \varepsilon$ & $\wedge \varepsilon / \wedge O$ & V & كمتر از •r & \multirow{6}{*}{ سن (سال) } \\
\hline \multirow[t]{5}{*}{$\mathrm{P}=\cdot / 10$} & IV/No & $91 / 70$ & $r$. & $r q-r$. & \\
\hline & $|N /| \varepsilon$ & $1 \cdot T / T_{0}$ & $r \varepsilon$ & $\varepsilon q-\varepsilon$. & \\
\hline & $1 V / 0 \varepsilon$ & $91 / 9 r$ & $\varepsilon r$ & $09-0$. & \\
\hline & $r \cdot 110$ & $9 r / 01$ & そ1 & $79-7$. & \\
\hline & T1/07 & $a r / v$. & $r$. & بيشتر از V ب & \\
\hline$t=\cdot / 77$ & $T / Y I$ & $90 / 21$ & va & مرد & \multirow{3}{*}{ جنسيت } \\
\hline$d f=10 r$ & T/M & $q r / \varepsilon r$ & v & زن & \\
\hline \multicolumn{5}{|l|}{$\mathrm{P}=\cdot / 0$} & \\
\hline$f=r / 7$. & IN/VV & $97 / 0 r$ & 10 & مجرد & \multirow{3}{*}{ وضعيت تأهل } \\
\hline \multirow[t]{2}{*}{$\mathrm{P}=\cdot / \cdot r$} & $r \mid / \cdot 1$ & $\wedge \mu / \Lambda \cdot$ & 110 & متاهل & \\
\hline & $I V / I V$ & $10 / \varepsilon \varepsilon$ & ro & بيوه / مطلقه & \\
\hline$f=1 / 9 r$ & $1 \varepsilon / 79$ & $9 T / M \Lambda$ & 29 & ابتدايى & \multirow{4}{*}{ تحصيلات } \\
\hline \multirow[t]{3}{*}{$\mathrm{P}=\cdot / r$} & $19 / \cdots$ & $9 \cdot / 21$ & そ & سيكل & \\
\hline & TT/TO & QV/AT & $\varepsilon$. & دييلم & \\
\hline & $19 / 99$ & $99 / 11$ & ro & دانشخاهى & \\
\hline $\mathrm{t}=\cdot \cdot \cdot \wedge$ & $19 / 29$ & $9 \varepsilon / \varepsilon r$ & rv & بله & \multirow{3}{*}{ تغيير شغل } \\
\hline $\mathrm{df}=10 r$ & $|1 / 9|$ & $9 \varepsilon / N r$ & $11 \mathrm{~V}$ & خير & \\
\hline $\mathrm{P}=\cdot / 9 r$ & & & & & \\
\hline
\end{tabular}

جدول شماره ا: شاخص هاى عددى خودكارآمدى در بيمار ان داراى استومى توارشى بر حسب مشخصات جمعيت شناختى

ممكن است از رفتارهاى بهداشتى، بهتر بيروى كنند كه اين نشان دهندهى انطباق آنان از برنامهى درمانى است (19).

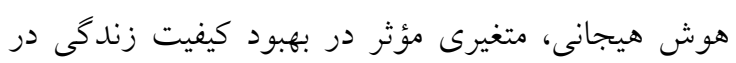

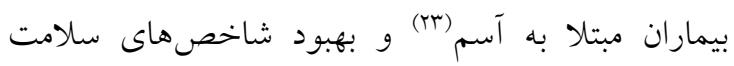

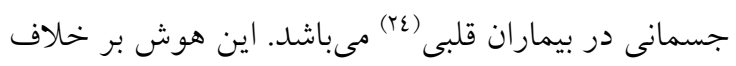

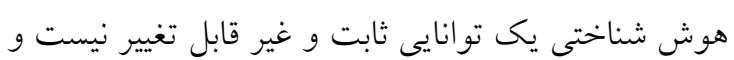

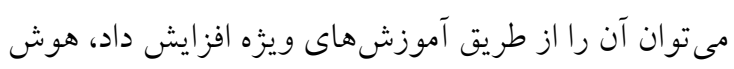

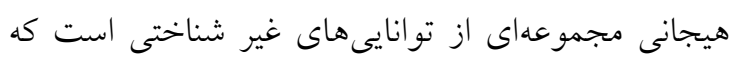

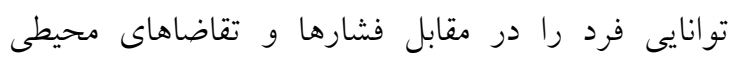

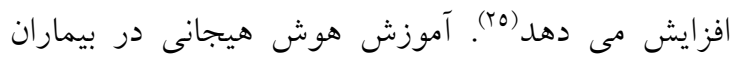

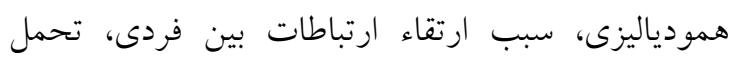

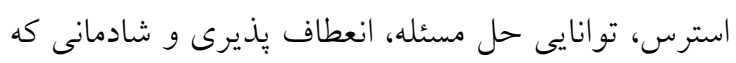

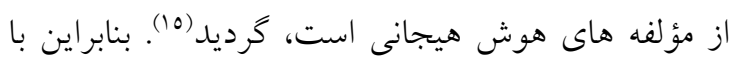
توجه به اينكه هوش هيجانى بالا مى تواند به بيماران داراى هوديجاني

\section{بحث و نتيجه تيرى} نتايج مطالعه حاضر در رابطه با "ميانخين نمره هوش

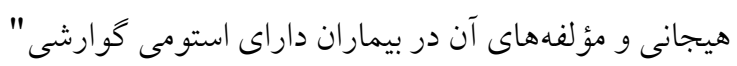

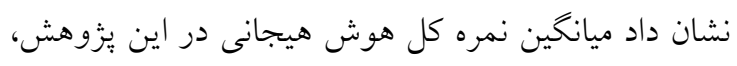

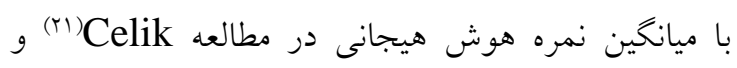

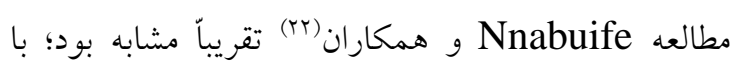

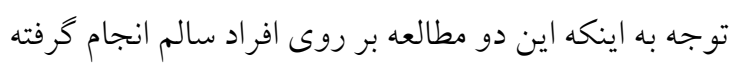

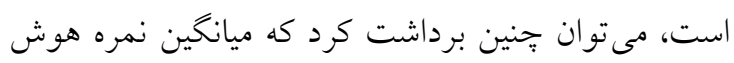

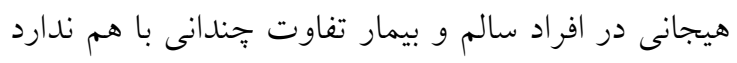
و ابتلا به بيمارى باعث ايجاد تغيير در سطح هوش هيجانى

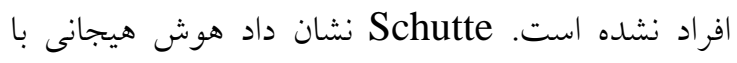

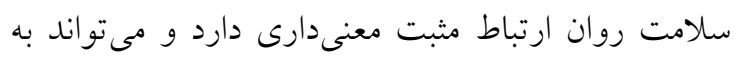
عنوان سبرى در مقابل بيمارىهاى جسمى عمل كند، به رونه علاوه افرادى كه داراى هوش هيجانى بالاترى هستند، 
اين باور و اطمينان به توانايى خود در فرد، باعث حساسيت بيشتر وى نسبت به سلامت استوما و انجام موفقيت آميز

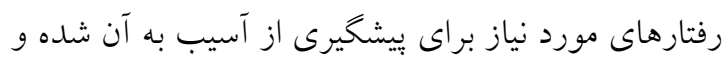

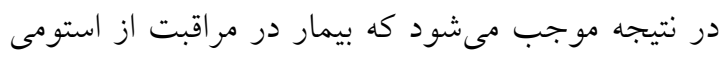

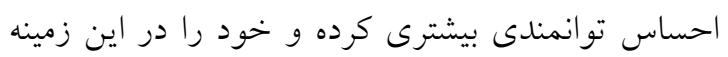

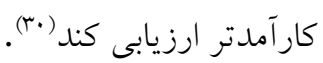

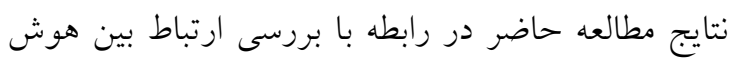

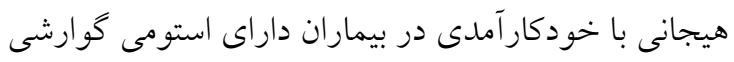

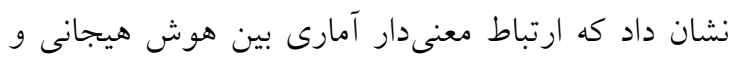

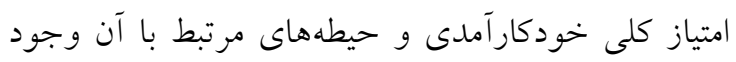

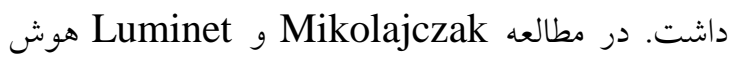
هيجانى رابطه مثبى با خودكار آمدى داشت و هر دو متغير،

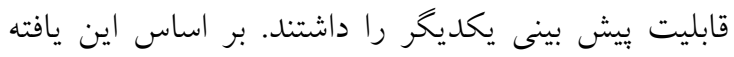

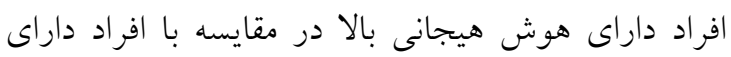
هوش هيجانى بايين، در هملى موقعيتها عملكرد بهترى

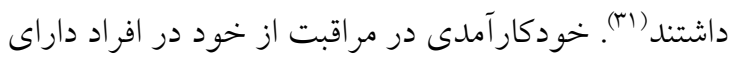

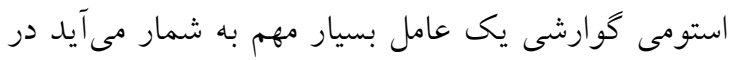

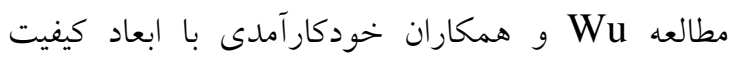
زندكى بيماران داراى استومى گوارشى ارتباط مثبت و معنى

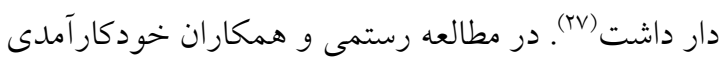

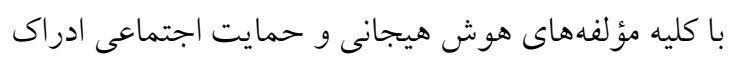

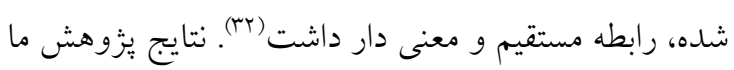

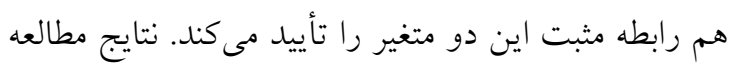

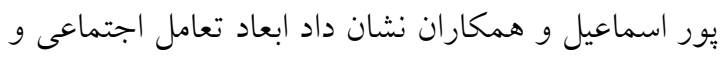

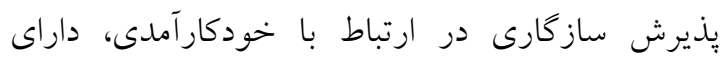

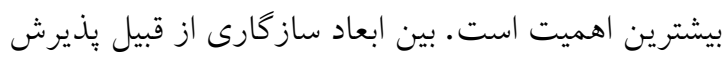

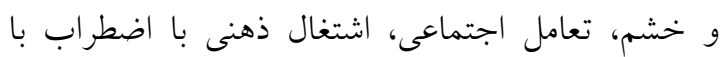

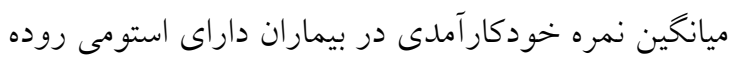

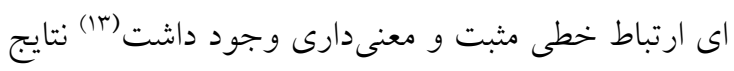

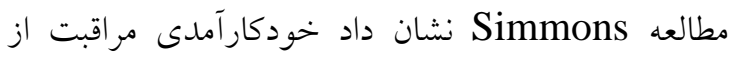

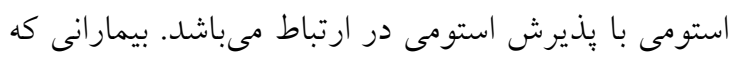

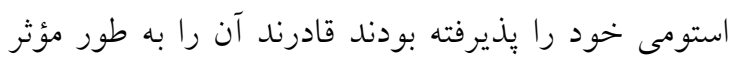

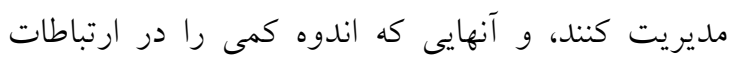
اجتماعىشان تجربه كردند و يا هيج اندوهى را در ارتباطات
استومى كوارشى جهت بيروى از رفتارهاى بهداشتى كمى

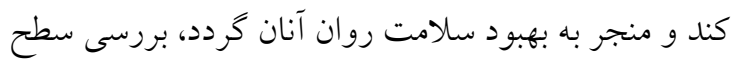
هوش هيجانى و تقويت آن با اقدامات آموزشى بعدى لازم و ضرورى به نظر مىرسد.

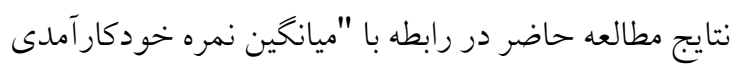

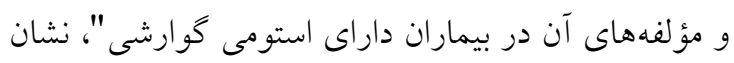

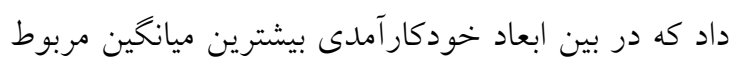

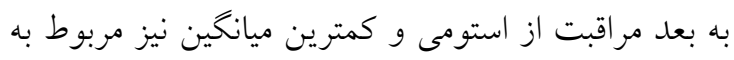

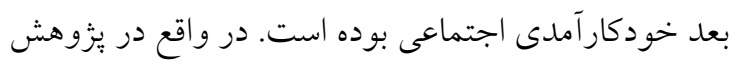

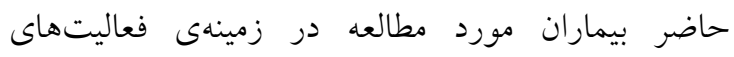
اجتماعى مرتبط با استومى باورهاى ضعيفترى از

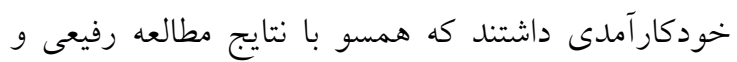

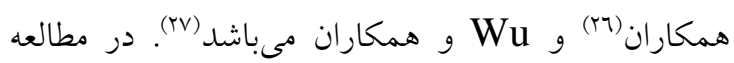
محسنى يويا و همكاران ميانخين نمره خودكار آمدى بيماران

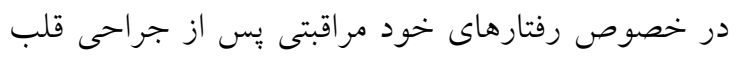

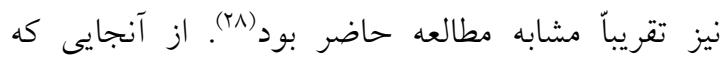

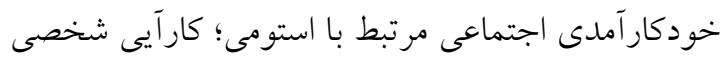

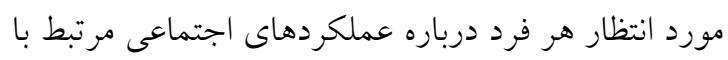

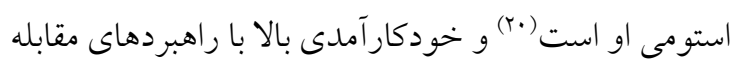

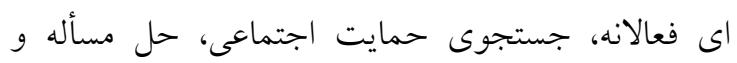

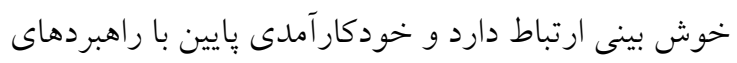

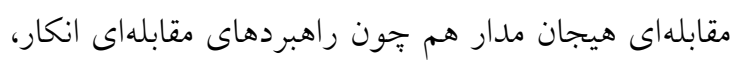

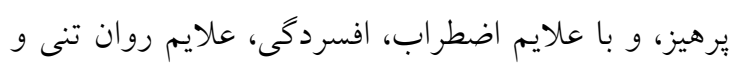

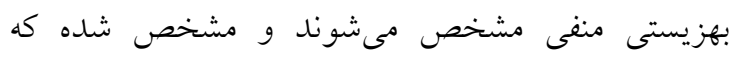

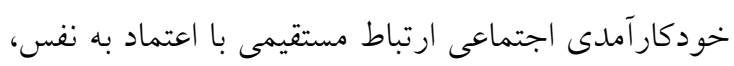
رضايت از زندگى و خوش بينى افراد دارد(به)؛ بنابراين

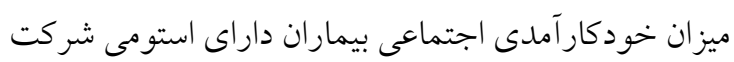
كننده در يزّوهش حاضر نياز به بررسى و تأمل بيشتر دارد

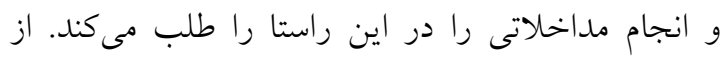

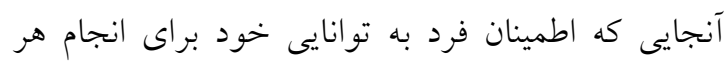
رفتارى (از جمله بيشخيرى از خونريزى يا صدمه به استوما)

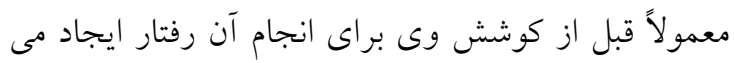

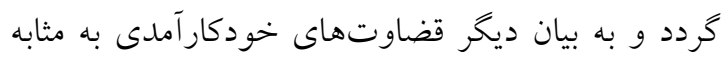

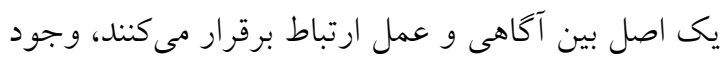


حاضر در مطالعه Tajpreet نيز ارتباطى بين هوش هيجانى و مشخصههاى جمعيت شناختى يافت نشد (T) در مطالعه هونه و همكاران بر روى جراحان ارتويدى، بين جنسيت

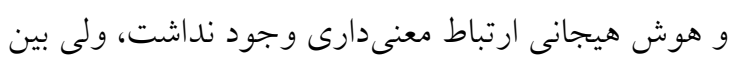
كروههاى سنى و تحصيلات با هوش هيجانى ارتباط معنى ارنى

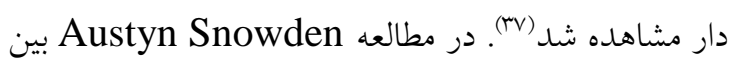

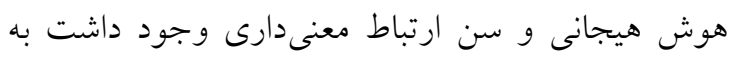

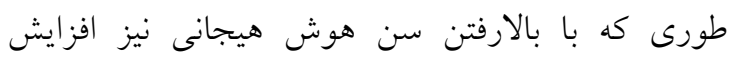

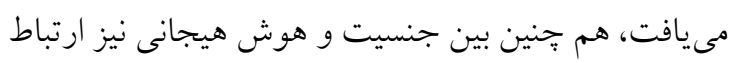

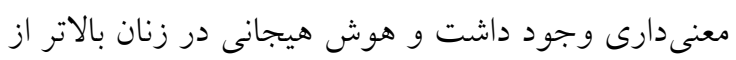

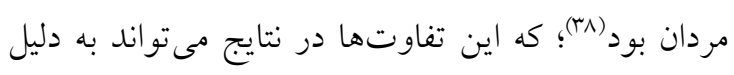
تفاوت در جامعه نمونه باشد. هوش هيجانى جنبه ديخرى نقاون

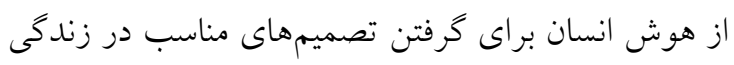

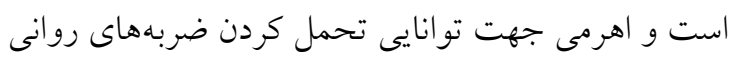

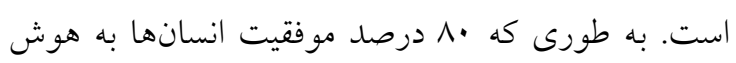

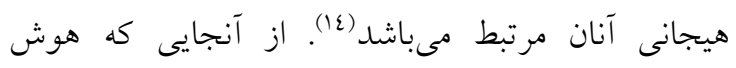

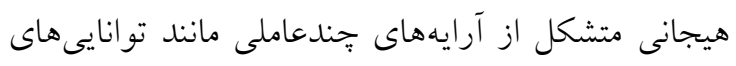

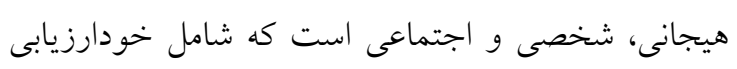

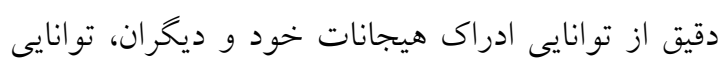

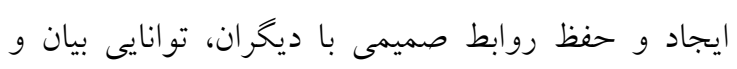

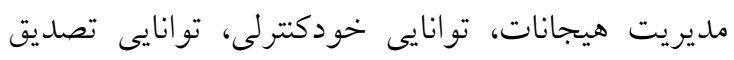

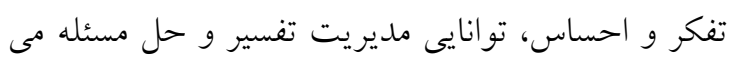

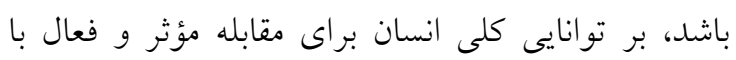

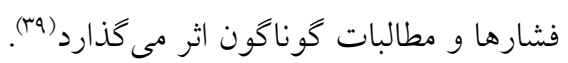
نتايج مطالعه حاضر در رابطه با ارتباط مشخصات جمعيت مونيت

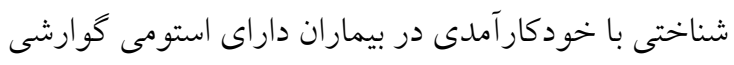

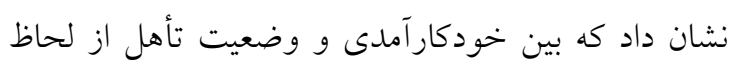

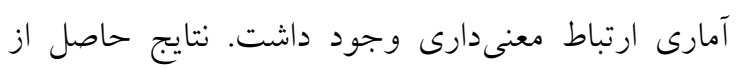

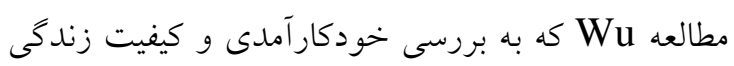

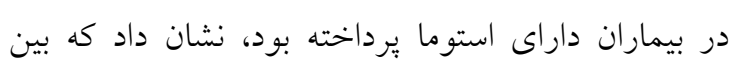

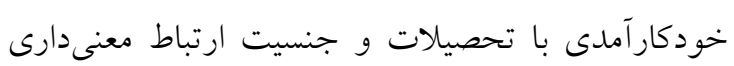

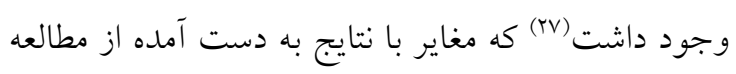
حاضر بود؛ اين تفاوت ممكن است به دليل ساختار متفاوت دو مطالعه و خصوصاً مكان متفاوتى كه اين دو مطالعه انجام
اجتماعى شان تجربه نكردند، بيشتر احتمال داشت كه شش

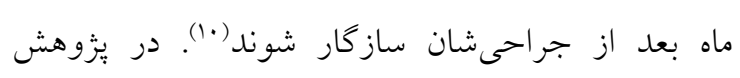
Bazalinski

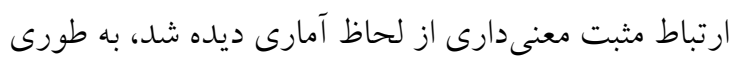

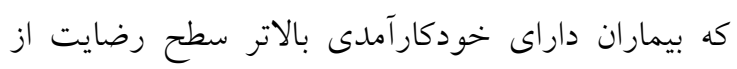

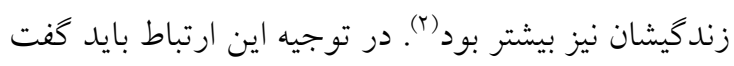
كه هوش هيجانى مجموعهاى از مؤلفههاى هيجانى مى باشد

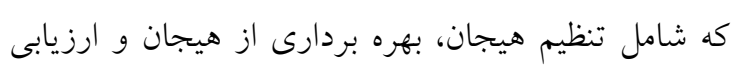

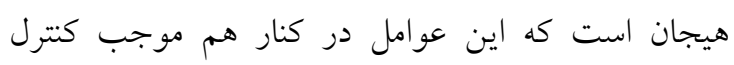

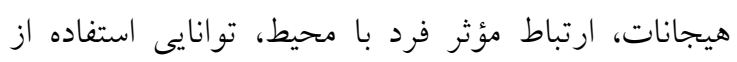

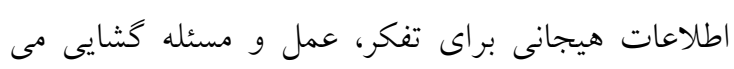

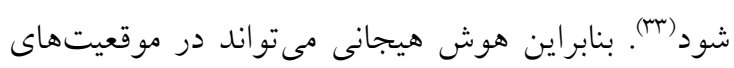
مختلف به فرد، براى كنترل هيجانات، تصميم گيرى صحيح و عملكرد مناسب كمك كند.

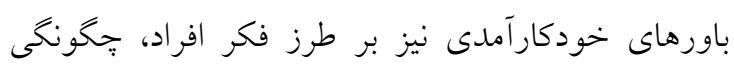

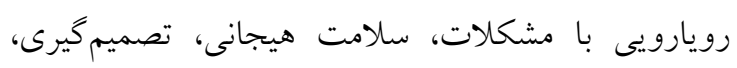

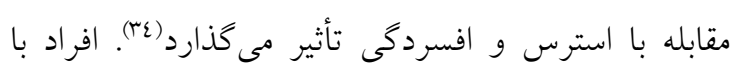

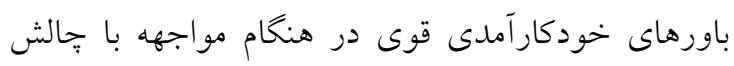
هاى زندگى مؤثر تر، هيجانات خود را تنظيم مى نمايند (r).

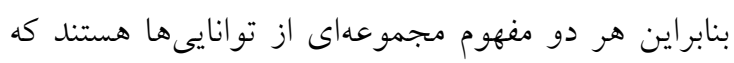

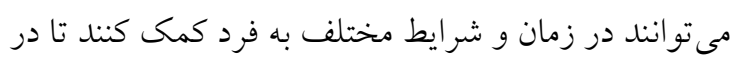

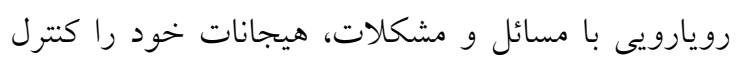

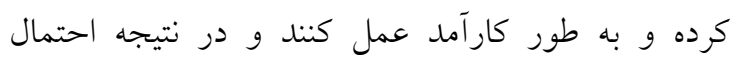

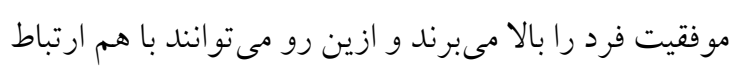

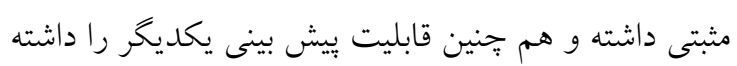

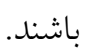
نتايج مطالعه حاضر در رابطه با ارتباط مشخصات جمعيت

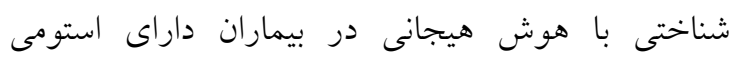

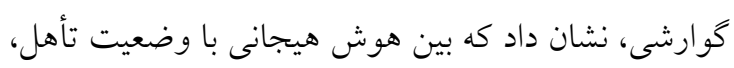

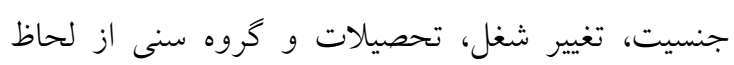

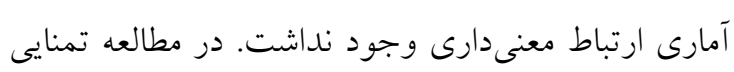
فر و همكاران بين هوش هيجانى و جنسيت دانشجويان

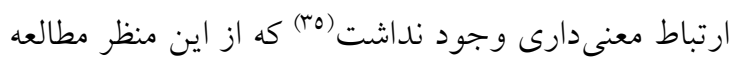
حاضر همسو با نتايج اين مطالعه مىباشد. همانند مطالعه 


$$
\begin{aligned}
& \text { اختلال شده بود، در مداخلات آموزشى بعدى به اين مؤلفه } \\
& \text { توجه بيشترى مبذول گردد. } \\
& \text { در تفسير نتايج اين مطالعه بايد در نظر داشت كه نمدون نمونه } \\
& \text { كيرى به روش در دسترس انجام گرفته است، هم تجنين }
\end{aligned}
$$

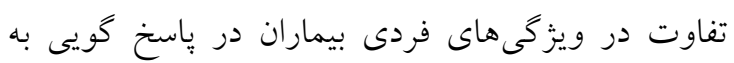

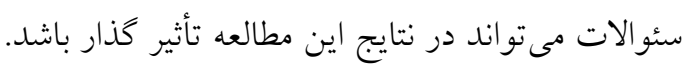

$$
\begin{aligned}
& \text { تعارض منافع: هيج گونه تعارض منافع توسط نويسند كان } \\
& \text { بيان نشده است. } \\
& \text { تقدير و تشكر } \\
& \text { اين مقاله منتج از يايان نامه مقطع كارشناسى ارشد بِرستارى }
\end{aligned}
$$

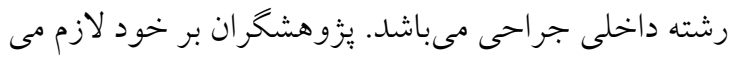

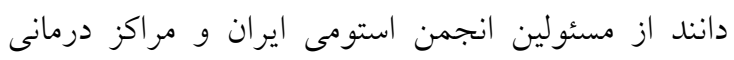

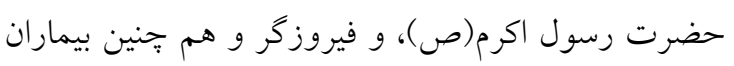

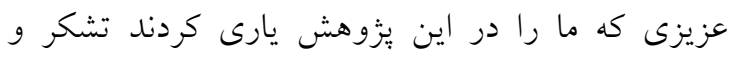

$$
\begin{aligned}
& \text { قدردانى كنند. }
\end{aligned}
$$

\section{References}

1- Gozuyesil E, Taylan S, Manav AI, Akil Y. The Evaluation of Self-Esteem and Sexual Satisfaction of Patients with Bowel Stoma in Turkey. Sexuality and Disability. 2017;35(2):157-69.

2- Bazaliński D, Sałacińska I, Więch P, Kózka M. Life satisfaction and self-efficacy in patients with stoma. Progress in Health Sciences. 2014;4(2):22-30.

3- Simmons KL, Smith JA, Bobb KA, Liles LL. Adjustment to colostomy: stoma acceptance, stoma care self-efficacy and interpersonal relationships. J Adv Nurs. 2007;60(6):627-35.

4- Sheetz KH, Waits SA, Krell RW, Morris AM, Englesbe MJ, Mullard A, Campbell DA, Hendren S. Complication rates of ostomy surgery are high and vary significantly between hospitals. Dis Colon Rectum. 2014 May;57(5):632.

5- adel mm, ashouri e, moula da, aghaei s. Psychological experiences of patients with surgical stoma (cholostomy): a phenomenological study. behav sci. 2008;6(12):119-127. [Persian]

6- Mahjoubi B, Mohammadsadeghi H, Mohammadipour M, Mirzaei R, Moini R. Evaluation of psychiatric illness in Iranian stoma patients. Journal of psychosomatic research. 2009;66(3):24953. [Persian]

7- Geng Z, Howell D, Xu H, Yuan C. Quality of Life in Chinese Persons Living With an Ostomy. J Wound Ostomy Continence Nurs. 2017;44(3):249-56.

8- Su X, Qin F, Zhen L, Ye X, Kuang Y, Zhu M, Yin X, Wang H. Self-efficacy and Associated Factors in Patients With Temporary Ostomies. J Wound Ostomy Continence Nurs. 2016;43(6):623-9.

9- Krouse RS, Grant M, Wendel CS, Mohler MJ, Rawl SM, Baldwin CM, Coons SJ, McCorkle R, Ko CY, Schmidt CM. A mixed-methods evaluation of health-related quality of life for male veterans with and without intestinal stomas. Dis Colon Rectum. 2007;50(12):2054-66.

10-Simmons KL. A view from here: psychosocial issues in colostomy care. J Wound Ostomy Continence Nurs. 2014;41(1):55-9. 
11-Rafii F, Naseh L, Yadegary MA. Relationship between Self-efficacy and Quality of Life in Ostomates. Iran Journal of Nursing. 2012 Jun 1;25(76): 64-76. [Persian]

12- Campbell A, Ntobedzi A. Emotional intelligence, coping and psychological distress: a partial least squares approach to developing a predictive model. E J Appl Psychol. 2007;3:39-54.

13- Pouresmail Z, Heshmati Nabavi F, Sadeghi T, Shafiee Jafarabadi MN, Voshani B, Reza H. Correlation between adjustment and self-efficacy in patients with intestinal ostomy. Journal of hayat. 2017;22(4):300-11.[Persian]

14- Luque-Reca O, Pulido-Martos M, Lopez-Zafra E, Augusto-Landa JM. Emotional intelligence and health-related quality of life in institutionalised Spanish older adults. International Journal of Psychology. 2015;50(3):215-22.

15- Yarahmadi F, Ghasemi SF, Forooghi S. The effects of emotional intelligence training on anxiety in hemodialysis patients. IJPN. 2015; 3(12).[Persian]

16- Rosenstein, A. and Stark, D. Emotional Intelligence: a critical tool to understand and improve behaviors that impact patient care. JPCPY.2015; 2(1): 1-4.

17- Martínez González AE, Piqueras Rodríguez JA, Ramos Linares V. Emotional intelligence in physical and mental health. EJREP. 2010;8(2):861-90.

18- Williams R. Anger kills: seventeen strategies for controlling hostility that can harm your health. Crown; 2012 Nov 14.

19- Schutte NS, Malouff JM, Thorsteinsson EB, Bhullar N, Rooke SE. A meta-analytic investigation of the relationship between emotional intelligence and health. Personality and individual differences. 2007 Apr 1;42(6):921-33.

20- Bekkers MJ, Van Knippenberg FC, Van Den Borne HW, van Berge-Henegouwen GP. Prospective evaluation of psychosocial adaption to stoma surgery: the role of self-efficacy. Psychosomatic Medicine. 1996;58(2):183-91.

21-Celik GO. The relationship between patient satisfaction and emotional intelligence skills of nurses working in surgical clinics. Patient Prefer Adherence. 2017;11:1363.

22- Nnabuife, E., Chukwuemeka, O., Chinwendu, U., Ephraim I, D., Ikechukwu' E. The Relationship between Self-esteem and Emotional Intelligence among Undergraduate Medical Students of Imo State University, Owerri, Nigeria. Int J Brain Cogn Sci. 2018; 7(1):1-8.

23-Sanchooli M, Fathi Aghdam G, Rezaishirazi R, Sanchooli J. The effect of emotional intelligence training on the quality of life in asthmatic patients. Int J Basic Sci Med. 2016;1:67-71.

24- Mokhtari Z, Alipor A, ExiriFard M. Effect of Emotional Intelligence on physical health among heart patient's bed ridden. Journal of Jahrom University of Medical Sciences. 2014;12(2). [Prsian]

25- Bar-On R. The Bar-On model of emotional-social intelligence (ESI). Psicothema. 2006;18:13-25.

26- Rafii F, Naseh L, Parvizy P. Self-efficacy and its Dimensions in Patients with Intestinal Stoma. Iran Journal of Nursing. 2013;26(83):10-8. [Persian]

27- Wu HK, Chau JP, Twinn S. Self-efficacy and quality of life among stoma patients in Hong Kong. Cancer Nursing. 2007;30(3):186-93.

28- Mohseni PH, Majlessi F, Shojaeizadeh D, Rahimi FA. The Effect of Educational Intervention Based on the Pender's Health Promotion Model on Patients'self-Efficacy for Self-Care Behaviors Following Heart Surgery.. Iran J Nurs Midwifery Res. 2017; 12(3): 16-23. [Persian]

29- Quintana JM, González N, Bilbao A, Aizpuru F, Escobar A, Esteban C, San-Sebastián JA, de-laSierra E, Thompson A. Predictors of patient satisfaction with hospital health care. BMC health services research. 2006;6(1):102.

30- Bastani F, Heidarian A, Vafaie M, Kazemnejad A, Kashanian M. The effect of relaxation training based on self-efficacy theory on mental health of pregnant women. Ijpcp. 2006; 12(2): 109-116. [Persian]

31- Mikolajczak M, Luminet O. Trait emotional intelligence and the cognitive appraisal of stressful events: An exploratory study. Personality and individual differences. 2008;44(7):1445-53.

32- Rostami R, Shahmohamadi K, Ghaedi G, Besharat MA, Akbari Zardkhaneh S, Nosratabadi M. Relations among self-efficacy, emotional intelligence and perceived social support in university students. The Horizon of Medical Sciences. 2010;16(3):46-54. [persian] 
33- Salovey P, Mayer JD. Emotional intelligence. Imagination, cognition and personality. 1990;9(3):185-211.

34- Tamannaeifar M, Leis H. Relationship between Self-Efficacy and Academic Achievement among High-School Students. Int J Psychol Behav Res. 2014;3(2):89-95.

35- Tamannaifar MR, Sedighi Arfai F, Salami Mohammadabadi F. Correlation between emotional intelligence, self-concept and self-esteem with academic achievement. Education Strategies in Medical Sciences. 2010;3(3):121-6..[Persian]

36- Tajpreet K, Maheshwari SK. Relationship of emotional intelligence with self-esteem among adolescents. Indian Journal of Psychiatric Nursing. 2015;10(1):1-6.

37- Chan K, Petrisor B, Bhandari M. Emotional intelligence in orthopedic surgery residents. Can J Surg. 2014;57(2):89.

38- Snowden A, Stenhouse R, Young J, Carver H, Carver F, Brown N. The relationship between emotional intelligence, previous caring experience and mindfulness in student nurses and midwives: a cross sectional analysis. Nurse Educ Today. 2015;35(1):152-8.

39- MirzaeI J, Babaei R, Alizadegan ML, Mahmoudi F, Shaghaghi P. Investigation of the Effectiveness of Emotional Intelligence Training on the General Health and Self-Esteem in Adolescents with Cerebral Palsy. Journal of Exceptional children Empowerment. 2017; 8(22): 37-49. [Persian] 